\title{
Alguns Aspectos da Hermenêutica Filosófica e Jurídica*
}

Some Aspects from Philosophic and Juridic Hermeneutic

\author{
Ollaxcia eAndrea Orihxing \\ Advogada, Professora da UCS, Especialista em Direito Público pela UNIJUI e \\ Mestranda em Direito pela UFPR.
}

Palavras-chave: hermenêutica, hermenêutica filosófica, hermenêutica jurídica

Key-words: hermeneutic, hilosophic hermeneutic, juridic hermeneutic

E-mail: buhring@uol.com.br

\section{SUMÁRIO}

\section{Introdução;}

1 Hermenêutica filosófica; 1.1 Compreensão, aplicação e interpretação; 1.2 Aristóteles: sua hermenêutica sempre atual; 1.3 A viragem lingüística; 1.4 A linguagem no mundo; 1.5 A questão do método;

\section{Hermenêutica jurídica; 2.1 Interpretação} do direito; 2.2 Sistema jurídico; 2.3 Método sistemático e tópico retórico; 2.4 Hermenêutica jurídica no Brasil; 2.5 Hermenêutica jurídica crítica;

\section{Considerações finais;}

Referências bibliográficas.

\section{RESUMO}

A abordagem da "Hermenêutica Filosófica" com ênfase na compreensão, aplicação e interpretação é fundamental, pois com a viragem lingüística, inverteu-se o objeto do fundamento, rompendo a relação sujeitoobjeto para sujeito-sujeito, assim, a verdade ligada ao método, é um caminho para a busca da racionalidade. Por outro lado, é observado com a "Hermenêutica Jurídica", a importância da sistemática, bem como a hermenêutica jurídica crítica, comprometida, trazendo o intérprete como agente da transformação social.

\section{ABSTRACT}

The approach of "Philosophic Hermeneutic", with emphasis on understanding, applying and interpretation, is fundamental, because with the linguistic turn, the object of the fundament breaks the relationship between subject-object, turning to subjectsubject, so, the true linked to the method is one way for the search of rationality. On the other way, is observed that the systematic is important for the "Juridic Hermeneutic", so far the critical juridic hermeneutic is engaged, and arise the interpreter as an agent of socialtransformation.

* Monografia apresentada na disciplina de Filosofia do Direito, como requisito parcial à conclusão do curso de Mestrado Interinstitucional em Direito, Universidade Federal do Paraná - Universidade de Caxias do Sul, com professor Dr. CELSO LUIZ LUDWIG. 


\section{Introdução}

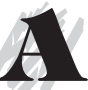

hermenêutica representa a mais importante forma de interpretação do sentido das palavras e ciências. E, por uma questão didática, separou-se o desenvolvimento do trabalho em três momentos, ou épocas históricas: ${ }^{1}$ Ser, Consciência e Linguagem. Dessa forma, estando a hermenêutica inserida no terceiro momento, ou seja, na linguagem, bem sabemos que esta divisão não é pacífica, pois segundo alguns doutrinadores a história não pode ser dividida paradigmaticamente. Nesse sentido, poderíamos ainda analisar um quarto paradigma: o da Vida, estudado por HENRIQUE DUSSEL, ${ }^{2}$ que se estrutura a partir de uma visão, uma ideologia apontada. Tal paradigma, no entanto, não significa a superação da linguagem.

Trabalha a hermenêutica com uma categoria central: a da Totalidade. Esta categoria será utilizada como sustentabilidade para o entendimento do primeiro, do segundo e do terceiro paradigma, ou seja, estes caracterizam-se como Totalidade e o quarto paradigma seria o da Universalidade. Essa constatação é possível, segundo ERNILDO STEIN, porque a filosofia tem "como tarefa fundamental desenvolver um discurso sobre a totalidade e essa totalidade é o mundo que envolve, como condição de possibilidade, todos os discursos cientí- ficos. A filosofia, portanto, fala sobre o mundo e as ciências falam dentro do mundo". 3

Para a concretização deste trabalho faz-se necessário o entendimento do objeto central de investigação - a hermenêutica. Dessa forma, "a palavra 'hermenêutica' tem sua raiz no deus da mitologia grega 'Hermes'. A imagem do deus alado está ligada a 'apoio, cipo, coluna'". ${ }^{4}$ Este é identificado como um deus egípcio, que fazia a interpretação entre a linguagem dos deuses e a dos homens comuns-mortais. Hermes é o mensageiro dos deuses. A norma é produto de Hermes a partir da concretização do sentido de um texto atribuído pelos deuses.

A base de nossa investigação é as contribuições hermenêuticas de HANSGEORG GADAMER, ou seja, este autor "pretende liberar a hermenêutica da alienação estética e histórica para estudála em seu elemento puro da existência humana. As investigações de GADAMER se dirigem ao estudo das condições de possibilidades da interpretação e da compreensão, em especial no âmbito das ciências humanas, estabelecendo características e pressupostos fundantes de uma teoria geral da compreensão, de matriz nitidamente heideggeriana", efetuando o que se pode designar "de giro ontológico em

1 HABERMAS, J. Pensamento Pós-metafísico - estudos filosóficos. Rio de Janeiro: Tempo Brasileiro, 1990, p. 22.

2 DUSSEL, H. Ética da libertação na idade da globalização e da exclusão. São Paulo: Vozes, 1999.

3 STEIN, E. Aproximações sobre a hermenêutica. Porto Alegre: EDIPUCRS, 1996, p. 11.

4 BRANDÃO, J. de S. Mitologia grega. Vol. 2, Petrópolis: Vozes, 1987, p. 181. Ver também em SPAREMBERGER, R. F. L. Da hermenêutica à hermenêutica constitucional dos direitos fundamentais. Dissertação de Mestrado apresentada na UFPR em 19.06.2000, p. I. 
direção ao que vem a ser o objeto da compreensão: a linguagem". 5

Para atingir os objetivos desta pesquisa, propomo-nos a desenvolvê-la em dois capítulos. No primeiro, tratar-se-á da hermenêutica filosófica, abordando a idéia de compreensão, aplicação e interpretação. Ainda nesse capítulo abordar-se-á a hermenêutica aristotélica sempre atual; a viragem lingüística; a linguagem no mundo e a questão do método. No segundo capítulo, desenvolver-se-á aspectos da hermenêutica jurídica e da interpretação do direito, bem como o sistema jurídico, o método sistemático e o tópico retórico. Com essas considerações pretender-se-á analisar a hermenêutica jurídica no Brasil e suas principais implicações.

Dentro da hermenêutica filosófica, iremos trabalhar com a compreensão, sendo esta, antes de mais nada, uma pré-compreensão que se tem das coisas, é um juízo que trazemos conosco. A interpretação pode trazer "pré-conceitos", pré-concepções, influenciando nas valorações, não é um ato posterior e complementar à compreensão, pois compreender é interpretar. A aplicação é tão importante e essencial como a compreensão e a interpretação, pois compreender é também aplicar.

A atualidade hermenêutica em ARISTÓTELES se constata justamente porque ele é o filósofo que mais amplamente reflete sobre a questão do papel da razão frente à ética. Assim, com a viragem lingüística, ou a mudança no modo de se ver a filosofia e seu procedimento, havendo uma inversão do objeto para fundamento, rompendo-se com a relação sujeito-objeto, e, passando-se à relação sujeito-sujeito, acarretou que a filosofia da linguagem levanta a pretensão de ser filosofia primeira em relação à filosofia de ARISTÓTELES.

Passou-se, assim, do conhecimento para a linguagem, que é fundamental, sendo anterior à nossa presença no mundo. A questão do método é problemática, em razão de ser tido como o elo de ligação para a interpretação do Direito, pois toda verdade está ligada ao próprio método, que não é simplesmente uma via, um caminho, mas um caminho para a busca de algo - a racionalidade.

Dentro da hermenêutica jurídica, dáse destaque à interpretação do Direito como um todo, a exemplo de uma lei, que deve levar o intérprete (juiz) a aplicar ao caso concreto, o constante do ordenamento, necessitando, porém, de um conhecimento prévio, do caso em questão, que lhe é dado pelas partes, através das provas. Não se separa, portanto, a aplicação da compreensão. Entra aqui o sistema jurídico que é um conjunto de princípios e tópicos, normas e valores, com função de dar cumprimento tanto aos princípios como aos objetivos da Constituição. A ordenação sistemática é fundamental, assim como a tópica, que é uma técnica do pensamento que se orienta para o problema.

Por fim, nos propomos a esclarecer alguns aspectos importantes da herme-

5 GADAMER, H. G. Verdade e método. Traços fundamentais de uma hermenêutica filosófica. Tradução de MEURER, F. P. Revisão da tradução de GIACHINI, E. P. 3. ed., Petrópolis: Vozes, 1999. Cf. também em SPAREMBERGER, op. cit., p. 22. 
nêutica jurídica no Brasil e da hermenêutica jurídica crítica, que é comprometida, construtiva, no sentido do "justo", sendo o intérprete um agente desta transformação social.

\section{Hermenêutica filosófica}

É impossível falar em hermenêutica sem antes nos referirmos aos "paradigmas" e à "crise dos paradigmas" epistemológicos da história da filosofia, ou seja, paradigma é uma teoria fundamental, que é reconhecida pela comunidade científica, há um consenso, com delimitações nas investigações de uma disciplina, são as crenças, as percepções, os valores, o método. Todavia, isso é, na verdade, um estudo dos cientistas. A crise inicia-se com o surgimento de uma nova ciência, a ciência revolucionária. A verdade também é um paradigma, ou seja, é o que se aceita como verdade num determinado momento.

Para HABERMAS, não existe um "porto seguro", sendo que o único lugar é a linguagem. Passou-se do paradigma da filosofia do ser para o paradigma da filosofia da consciência, e deste para o paradigma da filosofia da linguagem, o que constitui um corte profundo. "A partir deste momento, os sinais lingüísticos, que serviam apenas como instrumento e equipamento das representações, adquirem, como reino intermediário dos significados lingüísticos, uma dignidade própria. As relações entre linguagem e mundo, entre proposição e estados das coisas, substituem as relações sujeitoobjeto". Transforma-se assim o trabalho de constituição do mundo em estruturas gramaticais deixando de ser tarefa da chamada subjetividade transcendental. ${ }^{7}$

Tais considerações nos remetem para a discussão do surgimento da hermenêutica filosófica. Nesse sentido, poderíamos demonstrar as contribuições hermenêuticofilosóficas de SCHLEIERMACHER, DILTHEY, BETTI, mas optamos como fio condutor deste texto por trabalhar com a obra de GADAMER, Verdade e Método. Para este autor, a hermenêutica indica uma "mobilidade fundamental de pré-sença, a qual perfaz sua finitude e historicidade, e a partir daí abrange o todo de sua experiência de mundo. Que o movimento da compreensão seja abrangente e universal, não é uma construtiva de um aspecto unilateral, mas está, antes, na natureza da própria coisa”. Sua obra aborda três grandes partes: a análise da obra de arte, da história e da linguagem, e nelas diz que há um acontecer da linguagem. ${ }^{8}$

6 Segundo KUHN, T. S. A Estrutura das revoluções científicas. 3. ed., São Paulo: Perspectiva, 1992, defende a tese de que a ciência se transforma paradigmaticamente e não simples evolução do conhecimento científico. No prefácio, ele aduz: "Considero 'paradigmas' as realizações científicas universalmente reconhecidas que, durante algum tempo, fornecem problemas e soluções modelares para uma comunidade de praticantes de uma ciência”, p. 13. E no posfácio - 1969, ele menciona que "... na maior parte do livro o termo 'paradigma' é usado em dois sentidos diferentes. De um lado, indica toda a constelação de crenças, valores, técnicas, etc., partilhados pelos membros de uma comunidade determinada. De outro, denota um tipo de elemento dessa constelação: as soluções concretas de quebra-cabeças que, empregadas como modelos ou exemplos, podem substituir regras explícitas como base para a solução dos restantes quebra-cabeças da ciência normal”, p. 218.

7 HABERMAS, op. cit., p. 15.

8 GADAMER, op. cit., p. 16-17. 
Existem, nestes três níveis, da experiência da arte, do conhecimento histórico e da linguagem, verdades que não são produzidas pelo método lógico-analítico. "Temos, entretanto, um tipo de experiências produzindo uma verdade que não é de caráter lógico-semântico. Essa, no fundo, é a idéia da obra. E é um tipo de verdade à qual temos acesso por caminhos totalmente diferentes dos que estão estabelecidos pelo conhecimento científico em geral", são postas as idéias do que pode-se chamar de hermenêutica filosófica. ${ }^{9}$

\subsection{Compreensão, aplicação e interpretação}

GADAMER investiga o problema hermenêutico, de caráter filosófico e não procedimental, utiliza, assim, a hermenêutica como "técnica", sendo a primeira de todas as condições hermenêuticas "a précompreensão que surge do ter de se haver com a coisa em questão...". ${ }^{10} \mathrm{~A}$ interpretação pode vir carregada de "pré-conceitos", ou seja, pode trazer uma carga de verdade ou pode ser ultrapassada. Então, há sempre uma pré-compreensão anterior.

A hermenêutica quer, assim, ocupar o seu lugar, pois "sua tarefa não é desenvolver um procedimento da compreensão, mas esclarecer as condições sob as quais surge compreensão". Estas condições, no entanto, têm de estar dadas. E mais, "os preconceitos e opiniões prévias que ocupam a consciência do intérprete não se encontram à sua disposição, enquanto tais. Este não está em condições de distinguir por si mesmo e de antemão os preconceitos produtivos, que tornam possível a compreensão daqueles outros que a obstaculizam, os mal entendidos". ${ }^{11}$

Destaca-se muito o retorno da questão hermenêutica ao centro do debate filosófico, onde a filosofia é hermenêutica, ou seja, a razão passa a ser vista como uma razão hermenêutica. Definir razão como hermenêutica significa compreendê-la como razão prática. E procura mostrar que a "hermenêutica não é uma questão de método, pois o método é usado como ques tão", o problema hermenêutico se dividia na velha tradição da hermenêutica em três momentos, o que ele menciona como subtilitas, ou seja, as sutilezas, “... distingue-se uma subtilitas intelligendi, compreensão, de uma subtilitas explicandi, a interpretação, e, ... subtilitas aplicandi, a aplicação... esses três momentos deviam perfazer o modo de realização da compreensão". 12

9 STEIN, op. cit., p. 44. E, na p. 64, tece um comentário sobre o surgimento da hermenêutica filosófica: "segundo HEIDEGGER... nunca somos transparência. Sempre somos um projeto já projetado, somos um jogo que já sempre foi jogado. Essa é a idéia que GADAMER vai tomar de HEIDEGGER. Assim se faz uma passagem da situação hermenêutica para o acontecer da verdade... é esta passagem de Ser e tempo para o livro Contribuições para a filosofia, que vai marcar propriamente o surgimento da chamada Hermenêutica Filosófica. A GADAMER não interessa propriamente, em seu livro, aquilo que queremos e fazemos, mas aquilo que para além do que queremos e fazemos acontecer".

10 GADAMER, op. cit., p. 441.

11 Ibid., p. 442-443.

12 GADAMER, op. cit., p. 459. 
Assim, a interpretação "não é um ato posterior e oportunamente complementar à compreensão, porém, compreender é sempre interpretar, e, conseguinte, a interpretação é a forma explícita da compreensão". E, em relação a isso, "está também o fato de que a linguagem e a conceptualidade da interpretação foram reconhecidas como um momento estrutural interno da compreensão, com o que até mesmo o problema da linguagem passa de uma posição ocasional e marginal para o centro da filosofia". Então "a aplicação é um momento do processo hermenêutico, tão essencial e integrante como a compreensão e a interpretação". Finalizando este raciocínio, “... compreender é sempre também aplicar ...". 13

A aplicação é um momento do processo hermenêutico tão essencial e integrante como a compreensão e a interpretação. É o que se pode chamar de "círculo hermenêutico", não são lineares. Não existindo interpretação fora da aplicação. Então: se compreender é sempre interpretar, sendo conseqüentemente a interpretação a forma de compreensão, então o Ser que pode ser compreendido é linguagem, que já está pressuposto desde o início, pois desenvolve a idéia de que estamos envolvidos na linguagem, determinando a verdade ou falsidade das proposições.

A interpretação também é hermenêutica, é compreensão, e o fato de não termos acesso aos "objetos via significado, mas via significado num mundo histórico determinado, numa cultura determinada, faz com que não consigamos dar conta pela análise lógica de todo o processo de conhecimento. Ao lado da forma lógica dos processos cognitivos precisamos colocar a interpretação". ${ }^{14}$

Existem dois modos de compreender, segundo STEIN, que seriam o compreender de uma proposição e o compreender anterior, que é saber como se está no mundo, o existir, o sobreviver. $\bigcirc$ compreender é uma qualidade do ser humano, não uma qualidade natural, mas enquanto humano. "Podemos imaginar que existe um logos que se bifurca: o logos da compreensão da linguagem, que comunica e o logos no qual se dá o sentido, que sustenta a linguagem". ${ }^{15}$

Por outro lado, ${ }^{16}$ a hermenêutica não é apenas um problema epistemológico. ${ }^{17}$ Podemos falar, em geral, de vários aspectos da hermenêutica: há, primeiro, uma interpretação, uma compreensão ingênua,

13 Ibid., p. 459-461.

14 STEIN, op. cit., p. 18.

15 STEIN, op. cit., p. 27, menciona que HEIDEGGER irá chamar esse "primeiro logos da compreensão de uma proposição, de logos apofântico, o logos que se manifesta na linguagem. E o outro logos, aquele que se dá praticamente no compreender enquanto somos um modo de compreender, irá chamar de logos hermenêutico. Estes dois elementos, o logos apofântico e o logos hermenêutico irão constituir a distinção que dará material para que se possa depois falar numa hermenêutica filosófica".

16 Ibid., p. 46-47. E, acrescenta: "Podemos até dizer que o homem, o ser-aí, como HEIDEGGER vai dizer, não seria capaz de sentir se não tivesse esta capacidade antecipadora da compreensão. É isso que o filósofo vai introduzir no método que desenvolve, no objeto que se propõe a desenvolver, na revisão do método que expõe... compreender, só é possível na medida em que o homem é um 'ser-no-mundo'... compreender é um compreender algo como algo...", p. 59-60.

17 Epistemologia é uma teoria ou ciência da origem, natureza e limites do conhecimento. É o pressuposto do saber. 
ametódica, assistemática, depois, há uma interpretação de caráter gnosiológico, ${ }^{18}$ e há, enfim, a interpretação de caráter ontológico". ${ }^{19}$

Neste sentido, a compreensão que o homem tem de si mesmo e a compreensão que tem do ser é considerada uma compreensão limitada, pois não consegue dar conta nem do passado, nem do futuro. Portanto, não conseguimos compreender algo plenamente, porque lidamos com uma história que nos limita. ${ }^{20}$

Existe um laço estreito que na sua origem unia a hermenêutica filológica, teleológica e jurídica, e que somente as três juntas comportam o conceito pleno de hermenêutica. Assim, a "própria compreensão se mostrou como um acontecer, e filosoficamente a tarefa da hermenêutica consiste em indagar que classe de compreensão, e por que classe de ciência, é esta que é movida, por sua vez, pela própria mudança histórica". ${ }^{21}$

\subsection{Aristóteles: sua hermenêutica sempre atual}

A hermenêutica é sempre atual em ARISTÓTELES, porque ele é o filósofo que mais ampla e sistematicamente contribui para que se possa explorar as diferentes atribuições da razão. $\bigcirc$ Direito pertence ao mundo da racionalidade prática, e, para resolver questões práticas se exige também uma razão prática, sendo a razão hermenêutica, o que significa: compreendê-la como razão prática.

ARISTÓTELES tem a ética como "parte da ciência política e lhe serve de introdução. $\bigcirc$ objetivo da ética seria então determinante qual é o bem supremo para as criaturas humanas (a felicidade) e qual é a finalidade da vida humana (fruir esta felicidade da maneira mais elevada - a contemplação)". ${ }^{22}$

Afirma, ainda, que há duas faculdades racionais, a primeira, que permite contemplar as coisas cujos primeiros princípios são invariáveis, e a segunda, que permite contemplar as coisas passíveis de variação. Partindo deste pressuposto, de que o conhecimento baseia-se numa correspondente "semelhança ou afinidade entre o sujeito e o objeto de espécies diferentes, devem ser também especificamente diferentes. Uma destas duas faculdades racionais pode ser chamada de científica e a outra de calculativa, pois deliberar e calcular são a mesma coisa, mas ninguém delibera sobre coisas

18 Gnoseológico é o conhecimento.

19 Metafísica era chamada de Ontologia - onto = Ser, logia = estudo (filosofia do ser). A metafísica toma um elemento da realidade para explicar tudo a partir desse elemento. A metafísica é o estudo em torno das causas do ser.

20 STEIN, op. cit., p. 63. E aduz: "HEIDEGGER passa a dar ao elemento hermenêutico não apenas a idéia do compreender a si mesmo, a de compreender-se como poder-ser, mas ele passa a dar ao elemento hermenêutico também este caráter da não totalidade do compreender, de uma limitação do compreender...". E ainda, "A intenção da hermenêutica será esclarecer esse pano de fundo (por trás do conhecimento metódico) da verdade que está no acontecer da obra de arte, no acontecer da história e no acontecer da linguagem", p. 73.

21 GADAMER, op. cit., p. 460-462.

22 ARISTÓTELES. Ética a nicômacos. Trad. Mário da Gama Kury. 2. ed., Brasília: Ed. UNB, 1992, p. 11. 
invariáveis. A faculdade calculativa, portanto, é uma das faculdades da parte da alma dotada de razão".23

\section{Para GADAMER, ARISTÓTELES} tem uma teoria ética, e esta estrutura, esse desdobramento o interessa, mas como "teoria hermenêutica". Não recupera a "ética de ARISTÓTELES", mas a aplicação das reflexões que faz da ética para a hermenêutica, “... compreender é então um caso especial da aplicação de algo geral a uma situação concreta e particular... ". Com isso, "ganha especial relevância para nós a ética aristotélica,... É verdade que ARISTÓTELES não aborda o problema hermenêutico nem sua dimensão histórica, mas trata somente da apreciação correta do papel que a razão deve desempenhar na atuação ética... ".24

O interesse de GADAMER não é ético e sim hermenêutico, o problema do método está determinado pelo objeto, constituindo um postulado aristotélico geral e fundamental, mantendo-se "socrático na medida em que retém o conhecimento como momento essencial do ser ético, e o que nos interessa é justamente o equilíbrio entre a herança socrática-platônica e este momento do ethos a que ele mesmo deu validez. Pois também o problema hermenêutico se aparta evidentemente de um saber puro, separadamente do ser". ${ }^{25}$

Segundo LUDWIG, que diz: "Daí a atualidade hermenêutica de ARISTÓTELES, por ele defendida: o problema hermenêutico não pode estar separado do ser; não pode ser um saber puro. Nisto consiste a atualização, gadameriana da teoria aristotélica, sem que confunda a hermenêutica com o saber técnico, nem moral, embora tais formas de saber contenham a tarefa da aplicação, também". ${ }^{26}$

São enumeradas por BERTI, razões, ou formas de racionalidade, enfatizando a contribuição de ARISTÓTELES a este debate sempre atual sobre a crise da razão. São elas: 1. a apodítica, que é demonstrativa e a dialética, que é o dialogar; 2 . o método da física, que é a ciência; 3. o método da metafísica, que é a ciência suprema; 4. o método da filosofia prática, que procura instaurar um novo estado de coisas; e por fim, 5. a retórica, que são os discursos. Enfatiza, assim, a contribuição de ARISTÓTELES sobre a racionalidade, sobre a presumida crise da razão, seu valor e também seus limites, além da possibilidade de reconhecer diversas "formas" de racionalidade. E conclui dizendo que do complexo da teorização aristotélica, da ciência e inteligência, da sapiência e sabedoria, da arte, da dialética e retórica, que estas resultam, ser uma série extremamente rica de formas de racionalidade com diferentes graus de exatidão, rigor ou precisão, mas que todas são caracterizadas pelo argumen$\operatorname{tar}^{27}$

23 Ibid., p. 114.

24 GADAMER, op. cit., p. 465.

25 GADAMER, op. cit., p. 467.

26 LUDWIG, C. L. Razão hermenêutica. Texto Inédito, p. 83.

27 BERTI, E. As razões de ARISTÓTELES. São Paulo: Loyola, 1998, p. 187. 


\subsection{A viragem lingüística ${ }^{28}$}

No século XX, a linguagem passou a ser objeto de reflexão bem mais intenso, nas mais diferentes áreas do conhecimento. A viragem lingüística ocorreu em 1958/60. Nessa fase, a linguagem passou a assumir a função de possibilidade, de condição, e rompeu com a relação sujeito-objeto, passando-se à relação sujeito-sujeito.

Linguagem é a condição para que se possa pensar a inversão de objeto para fundamento. Viragem significa mudança, ou seja, mudança no modo de ver a filosofia e no modo de ver o seu procedimento. A conseqüência é que a filosofia da linguagem levanta a pretensão de ser filosofia primeira em relação à filosofia de ARISTÓTELES. Passou-se, assim, do conhecimento para a linguagem.

Para HABERMAS, a guinada lingüistica "colocou o filosofar sobre uma base metódica mais segura e o libertou das aporias das teorias da consciência”. E "neste processo configurou-se além disso uma compreensão ontológica da linguagem, que torna a sua função hermenêutica, enquanto intérprete do mundo, independentemente em relação aos processos intramundanos de aprendizagem e que transfigura a evolução dos símbolos lingüísticos inserindo-os num evento poético originário". ${ }^{29}$
STRECK faz uma crítica do Direito, no seu livro Hermenêutica jurídica e $(m)$ crise, fazendo uma análise da linguagem, que é uma forma de transmissão de pensamento, ou viragem lingüística da filosofia, da semiótica $=$ significado e a hermenêutica filosófica, abrindo assim caminho para sua hermenêutica jurídica crítica. ${ }^{30}$

\subsection{A Linguagem no mundo}

A linguagem no mundo é anterior à nossa presença no mundo a exemplo de uma criança, que se localiza no mundo e será um "ser-no-mundo", a partir de sua condição de possibilidade de compreender a linguagem, que é o dasein (ser aí igual ao ponto de partida para compreensão). Um outro exemplo é o caso de uma guerra mundial, que, se não se ficar sabendo, isto não existe para quem não sabe que há uma guerra, pois o mundo só é mundo a partir da possibilidade de dizer o mundo, ou seja, a partir da linguagem. Sem linguagem não há mundo. É por isso que "Deus" tira a linguagem dos homens na "Torre de Babel", pois ao tirar-lhes a linguagem, lhes tira o mundo, deixando assim, os homens sem ação, pois eles precisam renomear todos os objetos para poderem se entender, e é por isso que a linguagem surge da falta. É preciso sempre ter uma pré-compreensão. ${ }^{31}$

28 O autor GADAMER, op. cit., p. 559, utiliza o termo "virada ontológica"; o autor STRECK, op. cit., p. 137, utiliza o termo "viragem lingüística"; o autor HABERMAS, op. cit., p. 53, utiliza o termo "guinada lingüística", podendo ser encontradas ainda outras formas para designar o rompimento como: "giro", "reviravolta lingüística" ou "linguistic turn".

29 HABERMAS, op. cit., p. 16.

30 STRECK, L. L. Hermenêutica jurídica e $(m)$ crise - uma exploração hermenêutica da construção do direito. Porto Alegre: Livraria do Advogado, 1999.

31 STRECK, op. cit. 
Em GADAMER, o desenvolvimento do fenômeno da linguagem como a experiência humana no mundo é onde a hermenêutica encontra seu solo realmente ontológico, pois "na linguagem representase o próprio mundo. A experiência lingüística do mundo é 'absoluta'. Ultrapassa toda relatividade do 'pôr' o ser, porque abrange todo o ser em si, pouco importa em que relações (relatividades) se mostra. A lingüisticidade da nossa experiência do mundo precede a tudo quanto pode ser reconhecido e interpretado como ente". Acrescenta ainda que "a relação fundamental não significa, portanto, que o mundo se torne objeto da linguagem. Aquilo que é objeto do conhecimento e de seus enunciados se encontra, pelo contrário, abrangido sempre pelo horizonte do mundo da linguagem". Sendo que a lingüisticidade da experiência humana no mundo como tal, não inclui necessariamente a objetivação do mundo. ${ }^{32}$

Sobre o novo na hermenêutica, STEIN descreve "o ser humano como 'serno-mundo' que desde sempre já se compreende a si mesmo no mundo, mas só se compreende a si mesmo no mundo porque já antecipou sempre uma compreensão do ser. Compreensão do ser não é de um ser objetivo, objeto, mas compreensão da totalidade... um mundo que é a própria transcendência".33

STEIN, informa que GADAMER procura nos "sugerir que temos uma possi- bilidade de representação ou de descrição de uma totalidade e essa totalidade é totalidade da experiência de mundo". Havendo, assim, um universo fundamental do ser humano descrito por essa experiência, e isso quer dizer que a interpretação do mundo é a interpretação da condição fática do ser humano, e mais, "o fato de, ao lado da idéia de experiência,... usar a expressão acontecer, é o que mais choca a tradição analítica e a análise lógica... acontecer da verdade, esse é o grande escândalo da hermenêutica filosófica quando queremos falar nas ciências humanas, nas ciências de espírito". ${ }^{34}$

Para este, a hermenêutica apresentava uma pretensão de universalidade, assim como a dialética também demonstrava esta pretensão. Então, todos os elementos centrais da hermenêutica filosófica, "como a idéia do 'pré-conceito', a idéia de horizonte, a idéia da história efetual, a idéia da consciência da história efetual, a idéia da consciência histórica, a idéia de situação hermenêutica, todos esses elementos entram em questão quando se procura explicitar esta totalidade da linguagem que nos envolve e quando nos queremos apropriar dessa totalidade pela interpretação". Desta forma, a linguagem é nossa "constituição fundamental". 35

\subsection{A questão do método}

O método é tido como o fio condutor para interpretação do direito, toda verdade

32 GADAMER, op. cit., p. 653.

33 STEIN, op. cit., p. 61.

34 STEIN, op. cit., p. 70-73.

35 Ibid., p. 75-76. 
está ligada ao método, podendo ser dedutivo ou indutivo, pois é só através dele que se pode dizer o Ser. Eé neste campo que reinou (e reina) a "analítica de ARISTÓTELES", porque diz com o método da ciência.

Para LUDWIG, o termo método “indica 'caminho' (odos) para algo além (meta), raiz etimológica da metodologia, onde o logos indica a racionalidade condutora enquanto elemento fundante, regulativo e determinante. A partir dos sentidos etimológicos podemos desvelar conceitualmente no método uma relação intencional. Um caminho que conduz para; para além (meta)". Desta forma, o método não é só um meio. "É um caminho para ir em busca de algo, concepção assumida integral e hegemonicamente pelo modelo moderno de ciência. A relação intencional indicada pela 'busca de algo' sinaliza, ao mesmo tempo, para outros aspectos, qual seja, o do modo ou processo (talvez 'procedimento') adotado no transcurso do 'caminho'. Assim, o logos (a razão), agora no caso da metodologia, exibe a racionalidade do método". ${ }^{36}$

Temos "pré-conceitos" que trazemos conosco. Segundo informa GADAMER, "não existe compreensão que seja livre de todo preconceito, por mais que a vontade do nosso conhecimento tenha de estar sempre dirigida, no sentido de escapar ao conjunto dos nossos preconceitos". Então: para que se possa garantir a verdade, não basta a certeza que a utilização dos métodos científicos proporcionam. E, acrescenta, "isso vale especialmente para as ciências do espírito, mas não significa, de modo algum, uma diminuição de sua cientificidade, mas, antes, a legitimação da pretensão de um significado humano especial que elas vêm reivindicando desde antigamente". $\bigcirc$ que traduz que o "fato de que, em seu conhecimento, opere também o próprio daquele que conhece, designa certamente o limite do 'método', mas não o da ciência. $\bigcirc$ que a ferramenta do 'método' não alcança tem de ser conseguido e pode realmente sê-lo através de uma disciplina do perguntar e do investigar, que garante a verdade". 37

\section{Hermenêutica jurídica}

Segundo LUDWIG, HANS-GEORG GADAMER “enuncia a hermenêutica jurídica para além de qualquer outra, como paradigmática para o esclarecimento do fenômeno da compreensão". Eis que o "texto jurídico, uma lei por exemplo, interessa ao jurista a partir e em virtude de um determinado caso dado, ou pelo menos parcialmente dado". Portanto, para a aplicação é imprescindível o conhecimento histórico do sentido original do texto em questão. A inclusão da aplicação como momento da compreensão faz com que entre a hermenêutica jurídica e a dogmática jurídica exista uma relação de necessária preponderância da hermenêutica e é no sentido da aplicação de um texto jurídico, não se separa, portanto, a aplicação da compreensão. ${ }^{38}$

36 LUDWIG, C. L. A problemática questão do método. Texto inédito, p. 34.

37 GADAMER, op. cit., p. 709.

38 LUDWIG, C. L. Razão hermenêutica. Texto inédito, p. 82. 
Divergência interessante se estabelece entre a hermenêutica jurídica e a hermenêutica histórica em que o "jurista toma o sentido da lei a partir de e em virtude de um determinado caso dado. $O$ historiador jurídico, pelo contrário, não tem nenhum caso de que partir, mas procura determinar o sentido da lei, na medida em que coloca construtivamente a totalidade do âmbito de aplicação da lei diante dos olhos" ${ }^{39}$

A hermenêutica jurídica é um autêntico procedimento das ciências de espírito, pois tanto compreender como interpretar significam conhecer e reconhecer um sentido vigente, e, em toda compreensão histórica está implícito que a tradição fala ao presente e tem de ser compreendido nessa e como essa mediação. "O caso da hermenêutica jurídica não é portanto um caso especial, mas está capacitado para desenvolver à hermenêutica histórica todo o alcance de seus problemas e reproduzir assim a velha unidade do problema hermenêutico, na qual o jurista e o teólogo se encontram com o filólogo". 40

A primeira lei da hermenêutica "é no sentido de nenhum artigo, inciso, parágrafo ou alínea poderão ser entendidos de forma isolada; devem, sim, ser interpretados sob a ótica sistêmica, tanto inter, quanto intra-sistematicamente". ${ }^{41}$ A hermenêutica é de acordo com este pensamento "a realidade da realidade". ${ }^{42}$

\subsection{Interpretação do direito}

\section{Como ensina HANS KELSEN, há} duas formas de interpretação, uma é a interpretação autêntica, e a outra é a interpretação inautêntica ou (não autêntica). A autêntica é a "interpretação do Direito pelo órgão que o aplica", e a inautêntica é a "interpretação do Direito que não é realizada por um órgão jurídico, mas por uma pessoa privada e, especialmente, pela ciência jurídica". Desta forma, todos têm direito a produzir uma interpretação, mas há diferença entre interpretação de todos, que é a inautêntica e a dos juízes, que é a autêntica (pois estes impõem interpretação). ${ }^{43}$

Para KELSEN, é possível mais de uma interpretação, havendo diferentes possibilidades, existe uma pluralidade de normas possíveis para interpretação, a Lei é uma moldura, hoje o texto é uma moldura - há uma criação das possibilidades da hermenêutica "nos limites da moldura", pois o sujeito não faz o que deseja aleatoriamente, somente até os limites dessa "moldura". ${ }^{44}$

39 GADAMER, op. cit., p. 483. Cita ainda a hermenêutica jurídica, reformatória, romântica e teológica.

40 Ibid., p. 487-489.

41 STRECK, op. cit., p. 40.

42 PASQUALINI, A. Hermenêutica e sistema jurídico. Porto Alegre: Livraria do Advogado, 1999, p. 54.

43 KELSEN, H. Teoria pura do direito. Tradução de João Baptista Machado. 5. ed., São Paulo: Martins Fontes, 1996, p. 388. HANS KELSEN era neokantiano, um positivista, para o qual a legitimação da totalidade do ordenamento jurídico é conduzida pela norma fundamental (Grundnorm), possível de justificação racional, pois a racionalidade pura só mexe com a forma e não com o conteúdo. A Norma Fundamental passa uma idéia regulativa da juridicidade das demais normas, vem assim a Teoria Pura do Direito, purificada de qualquer ideologia, política, ou outra forma de ciência natural.

Ibid., p. 390-391. 
E, acrescenta: "Se por 'interpretação' se entende a fixação por via cognoscitiva do sentido do objeto a interpretar, o resultado de uma interpretação jurídica somente pode ser a fixação da moldura que representa o Direito a interpretar e, conseqüentemente, o conhecimento das várias possibilidades que dentro desta moldura existem". E, por fim, diz que a interpretação de uma lei não deve conduzir necessariamente "a uma única solução como sendo a única correta, mas possivelmente a várias soluções que - na medida em que apenas sejam aferidas pela lei a aplicar - tem igual valor, se bem que apenas uma delas se torne Direito positivo no ato do órgão aplicador do Direito - no ato do tribunal, especialmente". 45

No processo de interpretação se passa para a produção do sentido, enquanto a hermenêutica clássica busca reproduzir o sentido, a outra hermenêutica (condição de possibilidade de "estar-no-mundo") é produtiva, porque produz sentido. $O$ intérprete produz sentido, e esse sentido expressado pelo texto já é algo novo, é sempre um novo texto, hermenêutica não é uma técnica. $\bigcirc$ sistema é texto, não norma. Ela só acaba sendo norma a partir do momento em que passa para o lado da interpretação produtiva, sendo que entre o texto e a norma fica o processo hermenêutico, que é o modo de "ser-no-mundo". ${ }^{4}$

45 Ibid., p. 390-391.

46 STRECK, op. cit., p. 16.

47 STRECK, op. cit., p. 17.

48 FREITAS, J. A interpretação sistemática do direito. 2. ed., São Paulo: Melhoramentos, 1995, p. 34.

49 PASQUALINI, op. cit., p. 54. E, mais, "as regras, sem qualquer dúvida, iluminam o caminho do intérprete, mas elas são pequenas fontes de luz, e não o sol", p. 76.
As palavras da lei não são unívocas, são plurívocas, por isso "é necessário dizer que, pelo processo interpretativo, não decorre a descoberta do 'unívoco' ou do 'correto' sentido, mas, sim, a produção de um sentido originado de um processo de compreensão, onde o sujeito, a partir de uma situação hermenêutica, faz uma fusão de horizontes a partir de sua historicidade. Não há interpretação sem relação social". ${ }^{47}$

O papel que possui o juiz na interpretação é extremamente importante, pois é ele quem delimita o conteúdo das normas, mesmo que estas sejam "molduras", situando "fora da ciência jurídica a decisão tomada por considerações políticas... ". 48 Assim, "quem faz o sistema sistematizar e o significado significar são os intérpretes, razão pela qual interpretar é, também e principalmente, interpretar-se". ${ }^{49}$

O Direito deve ser visto no mundo, com suas "inter-relações e interações", sob pena de, "desnaturando-o, desumanizar-se o jurista, o juiz e a função judiciária". E, assim, a "superação do positivismo jurídico é indispensável à construção de uma hermenêutica material no Direito que permita transpareçam e se evidenciem os interesses em questão, demandando, inequivocamente, opções, que supõem de direito das situações em que se manifesjuízos valorativos sobre os dados de fato e 
tam. Nessa perspectiva o trabalho do juiz precisa ser criativo". 50

Segundo FREITAS, a interpretação sistemática do Direito “tem por objeto o sistema jurídico na sua condição de totalidade axiológica", sendo o interpretar a hierarquização dos sentidos "teleológicos dos princípios, das normas e dos valores, mais do que simplesmente esclarecê-los". E mais, a missão da hermenêutica consiste "não em tratar o intérprete como apenas passivamente reagente a um sistema posto, mas sim, em cuidar de prepará-lo para o árduo, penoso e nem sempre bem efetuado exercício de vigilância contínua quanto à conformidade fundamentada de suas decisões e subsunções normativas ao sistema jurídico vigente" ${ }^{51}$

São infinitas as possibilidades de interpretação, conservando a justa reserva para com o arbitrário e a irracionalidade. Assim, a hermenêutica acha-se, em "dupla oposição, por um lado, ao ceticismo e, por outro, ao dogmatismo. A sua resposta é uma só: a busca da melhor exegese... (= hierarquização axiológica) se revela espiralforme. Fazendo rotações em torno do seu núcleo principiológico, o sistema, a cada leitura ou releitura, expande-se a partir de si mesmo". Então, interpretar um texto legal significa, acima de tudo, ter que se decidir por uma entre muitas possíveis interpretações. ${ }^{52}$

\subsection{Sistema jurídico}

O sistema jurídico é reconceituado por FREITAS como "uma rede axiológica e hierarquizada de princípios gerais e tópicos, de normas e de valores jurídicos cuja função é a de, evitando ou superando antinomias, dar cumprimento aos princípios e objetivos fundamentais do Estado Democrático de Direito, assim como se encontram consubstanciados, expresso ou implicitamente, na Constituição". ${ }^{53}$ Assim, interpretar uma norma é interpretar o sistema por inteiro: qualquer exegese comete, diretamente ou obliquamente, uma aplicação da totalidade do Direito. "Inegável, pois, o valor para a hermenêutica jurídica da chamada ordenação sistemática, a qual decididamente não pode ser confundida com um mero elemento ou método interpretativo". 54

Neste sentido, também é importante analisar a reconceituação que FREITAS faz de interpretação sistemática do Direito, ou seja: é "uma operação que consiste em atribuir a melhor significação, dentre várias possíveis, aos princípios, às normas e aos valores jurídicos, hierarquizando-os num todo aberto, fixando-lhes o alcance e superando antinomias, a partir da conformação teleológica, tendo em vista solucionar os casos concretos". 55

50 AZEVEDO, P. F. de. Crítica à dogmática e hermenêutica jurídica. Porto Alegre: Fabris Editor, 1989, p. 71-74.

51 FREITAS, op. cit., p. 9 e 57.

52 PASQUALINI, op. cit., p. 54-55. E cita o exemplo da hermenêutica que assemelha-se a uma cordilheira, e não a uma planície, ou seja, sempre haverá boas ou más exegeses.

53 FREITAS, op. cit., p. 46.

54 Ibid., p. 53.

55 Ibid., p. 60. 
Uma interpretação sistemática realiza sempre uma hierarquização axiológica, ${ }^{56}$ fazendo preponderar, ora uma norma superior, ora (em caso de antinomia pendente), um princípio superior, "recorrendo-se, em todas as hipóteses, expressa ou ocultamente ao princípio da hierarquização, inclusive ao lidar com princípios e regras de prioridade, tendo em vista as exigências do próprio sistema, que reclama sejam dirimidas as controvérsias, sempre na certeza de que bem interpretar é concretizar a máxima justiça sistemática possível". ${ }^{57}$

Finaliza FREITAS dizendo que a interpretação sistemática é a interpretação jurídica, por essência. "Deve o intérprete, com sabedoria, contribuir para a descoberta e para a formação tópica do sistema jurídico. De outra parte, é irrenunciável a luta pela formação de um Direito dotado de concatenação interna, sendo este um desafio para aplicadores e legisladores: oferecer uma ordem que se deixe interpretar plástica e maleavelmente de modo a se manter respeitável e garantidora da segurança das relações jurídicas". Há no fundo uma necessidade de formação "consciente e séria do intérprete jurídico para a suma tarefa ético-jurídica que consiste em, diante das antinomias, alcançar o melhor e o mais fecundo desempenho da interpretação sistemática em todos os ramos, com o escopo de fazer promissora a perspectiva de um
Direito que se confirme dotado de efetiva coerência e de abertura..." Por fim, "um Direito visto, ensinado e aplicado como o lídimo sistema normativo do Estado Democrático". 58

\section{Para ALEXANDRE PASQUALINI,} a interpretação sistemático-transformadora funciona como "um saber consagrador, que procura a convergência de tudo, para que nenhum princípio, norma, valor ou precedente jurídico se isole dos demais, para que um se possa juntar aos outros, e todos possam atuar, mais e sempre, como um conjunto sistemático, aberto e substancial". ${ }^{59}$

Aduz, por fim, que essa hermenêutica sistemático-transformadora interpreta a si mesma, ao Direito, "como um instrumento cuja finalidade constitutiva está em servir de elemento de integração e de aproximação axiológicas: onde há clausura, leva a abertura; onde há antinomias, restaura a unidade; onde há lacunas, proporciona a completabilidade e onde há exuberância, oferece, enfim, o socorro, mais material do que formal, da hierarquização valorativa". Toda exegese, assim como todo sistema jurídico, "só poderão ser compreendidos no seu momento integrativo-hierarquizador e, em razão disso, mais próximos da senda do Direito visto como manifestação e concretização da dignidade do ser humano, na sua perene,

56 Ibid., p. 89, dá o conceito do princípio da hierarquização axiológica: "é o metacritério que ordena, diante inclusive de antinomias no plano dos critérios, a prevalência do princípio axiologicamente superior, ou da norma axiologicamente superior em relação às demais, visando-se a uma exegese que impeça a autocontradição do sistema conforme a Constituição e que resguarde a unidade de sintética dos seus múltiplos comandos".

57 FREITAS, op. cit., p. 110.

58 Ibid., p. 205.

59 PASQUALINI, op. cit., p. 101. 
desafiadora e verticalizante meta de perfectibilização no seio deste sistema maior chamado vida (zoé)" ${ }^{60}$

\subsection{Método sistemático e tópico retórico}

Tem por função os métodos de interpretação opor limites ao intérprete, delimitando a área das soluções justificáveis, além de evitar as arbitrárias.

Segundo THEODOR VIEHWEG "A tópica é uma técnica do pensamento que se orienta para o problema; os raciocínios giram em torno dos problemas; é um estilo de trabalho aporético; todo problema concreto provoca um jogo de suscitações, que se denomina tópica ou arte da invenção". Chama a Ciência do Direito de Jurisprudência, tendo como ponto de partida o caso concreto, partindo assim, do problema concreto para solucionar, em vez de partir da norma para interpretar. Problema é tudo o que venha a permitir dar mais de uma resposta além do entendimento prévio. Assim a "jurisprudência não se vincula com a ciência mas com a retórica. E a tópica tem uma posição secundária na ciência do direito, mas predomina na jurisprudência”. E, de acordo com este pensamento, o legislador ou intérprete teriam, por base, um tópico inicial "o que é justo aqui e agora". Redu- zindo-se os problemas à "aporia da justiça", e, mesmo assim, o esforço para conferir que a determinação do sistema jurídico nunca é completo. ${ }^{61}$

Sobre pensamento sistemático e da tópica, a conclusão à qual chega FREITAS é que existem várias soluções dentro do sistema jurídico, e "apenas nele e a partir dele devem ser procuradas, numa perspectiva que, certamente, não afasta a necessidade de aprimoramento de lege ferenda, mas desenganadamente conduz a uma perspectiva em que o Direito Positivo deve ser pensado, antes de tudo, como um sistema de princípios, ${ }^{62}$ normas e valores, com todas as sérias conseqüências metodológicas que daí advêm, inclusive para a colmatação de lacunas". Desta forma, respeitadas possibilidades não só residuais da tópica, na interpretação sistemática, em especial no combate às antinomias, constatando-se a falta ou insuficiência das "visões unilaterais, sobretudo em função de estas não darem conta do problema da unidade dinamicamente considerada do pensamento jurídico. Ademais, justamente por inexistir exclusão rígida entre o pensamento tópico e o sistemático, qualquer modalidade de interpretação, dado que hierarquizadora, denota a vocação unificadora e integradora do pensamento sistemático". ${ }^{63}$

60 PASQUALINI, op. cit., p. 155.

61 VIEHWEG, T. Tópica e jurisprudência. Tradução Ferraz Jr. T. S. Imprensa Federal (Coleção Pensadores Jurídicos Contemporâneos). Brasília: DIN, 1979, p. 203 e ss. E acrescenta: "A palavra topos significa 'lugar-comum'. Aporia significa 'falta de um caminho', situação problemática, onde a tópica oferece orientações de como agir em tais situações, a fim de não se ficar sem saída".

62 Cabe aqui citar o exemplo do $18^{\circ}$ Camelo, - integrante e ao mesmo tempo não integrante do sistema jurídico, onde os princípios gerais são colocados como um paradoxo. Retirado do livro de STRECK, op. cit., p. 87.

63 FREITAS, op. cit., p. 148-149. 
Contribui PASQUALINI com a assertiva de que é "sistemático, à proporção em que se estrutura como totalidade hierarquizada de normas, princípios e valores jurídicos teleologicamente encadeados; tópico, à medida que a intrínseca indeterminação e abertura de tais normas, princípios e valores jurídicos oferecem, dentro e a partir do sistema, várias possíveis exegeses ou projetos de sistematização". ${ }^{64}$

Por isso, não se pode afirmar "que a tópica é apenas um meio auxiliar do pensamento sistemático, como predicava CANARIS, tampouco que o sistema é um recurso, até certo ponto circunstancial, no esforço de resolução tópica do caso concreto, como insinuava VIEWEG". E, ainda, neste sentido, uma vez que, "em conjunção orgânica e, por isso, dialética, os valores são a alma das normas, parece impossível deixar de concluir que a tópica é a verdade do sistema, e o sistema, a verdade da tópica". Em suma, no Direito, "liberdade e vinculação originam-se de um mesmo e único processo interpretativo tópico-sistemático, onde a lucidez e a verticalidade da razão enfeixam-se como as reais fiadoras do sistema”. ${ }^{65}$

\subsection{Hermenêutica jurídica no Brasil}

No Direito brasileiro, prevalece como "regra metanormativa, extensiva e impositiva a toda a ordenação jurídica, o art. 5-, da LICC, que se projeta na perspectiva da eqüidade, da lógica do razoável e dos métodos teleológicos e histórico evolutivo". Conclui que "numa sociedade estratificada, altamente complexa, contraditória e muito desigual economicamente, aumentam as dificuldades para a avaliação do bem comum e dos fins sociais da lei, que calibram a justiça da interpretação e da decisão". ${ }^{66}$

Quando se menciona o paradigma epistemológico da filosofia da consciência, se diz que este acaba, morre, o que não acontece no sistema brasileiro, pois está vigorante ainda na relação do Direito brasileiro, porque o jurista brasileiro tradicional acha que a hermenêutica é um método e que ele é o sujeito principal, e que, através de seu código, ele pode dizer e definir o mundo. Ora, ele não é sujeito de nada, e sim as circunstâncias e condição de "serno-mundo". É essa questão mais ampla que se tem de trabalhar hoje no Direito, ou seja, romper com o paradigma epistemológico da filosofia da consciência. Portanto, "romper com este paradigma antigarantista de dogmática jurídica e/ou ultrapassar os obstáculos que impedem o resgate das promessas da modernidade é tarefa que se impõe aos juristas". ${ }^{67}$

Segundo STRECK, no campo jurídico brasileiro, a linguagem ainda tem um caráter "secundário, como terceira coisa que se interpõe entre sujeito e objeto, enfim, uma

64 PASQUALINI, op. cit., p. 124.

65 Ibid., p. 135-137.

66 ANDRADE, C. J. de. Hermenêutica jurídica no Brasil. São Paulo: RT, 1991, p. 261.

67 STRECK, op. cit., p. 213. 
espécie de instrumento ou veículo condutor de essências e corretas exegeses dos textos legais. Essa lógica do sujeito, é dizer, o ser é sempre em função do sujeito, que provém de Descartes, é rompida pela viragem lingüística”, (com WITTGENSTEIN e HEIDEGGER). "Lamentavelmente - e aí está assentada uma das faces da crise paradigmática -, o campo jurídico brasileiro continua sendo refratário a essa viragem lingüística". ${ }^{68}$

\subsection{Hermenêutica jurídica crítica}

No contexto da teoria crítica do direito, surge a hermenêutica jurídica crítica, que é comprometida, construtiva, no sentido do "justo", sendo que o intérprete é um agente desta transformação social, atuando assim como "criador". Essa teoria crítica do Direito fundamenta-se em um novo modelo de ciência, elaborado pela epistemologia contemporânea, em razão do questionamento efetuado pelos tradicionais paradigmas científicos. ${ }^{69}$

Em geral, diz-se que a hermenêutica não é crítica. Teríamos um pensamento crítico e um pensamento hermenêutico, "como se o pensamento crítico fosse aquele capaz de dar todas as razões de uma afirmação. E como se o pensamento hermenêutico fosse menor... ". E, pela visão "crítica dos textos a hermenêutica é capaz de ver nelas mais do que elas são capazes de ver. A tradição hermenêutica co- meçou a colocar a questão do ler entre as linhas, a descobrir, atrás do texto, o texto não escrito, na medida em que mais que a verdade do texto, no texto está o sentido que envolve, abrange e carrega a verdade do texto, através dos processos histórico e culturais". 70

De acordo com o pensamento de STEIN, a hermenêutica poderia parecer acrítica, ou até mesmo ingênua, mas pelo contrário, ela nos dá uma consciência crítica (aquela que não está inteiramente de acordo com o seu tempo) "na medida em que ela forma a nossa consciência histórica e nos permite assumir uma situação histórica determinada, o mais possível transparente em um momento determinado, através de fusão de horizontes e na diluição de horizontes, de maneira que não fiquem presos a um conjunto de 'pré-conceitos' dos quais não nos libertaremos inteiramente como seres históricos e fáticos". ${ }^{71}$

A razão hermenêutica por mais crítica que ela seja não tem a força-poder de eliminar os "pré-conceitos" e nas decisões judiciais o resultado é formado tanto por conceitos como por "pré-conceitos", onde o juiz aplica o silogismo e convicções. Desta maneira, a teoria crítica se coloca como algo real transformador, de forma que o "direito não é o passado que condiciona o presente, mas o presente que constrói o futuro". E, é por isso que a "fonte mais autêntica de

68 Ibid., p. 44.

69 COELHO, L. F. Lógica jurídica e interpretação das leis. 2. ed., Rio de Janeiro: Forense, 1981, p. 182 e 308.

70 STEIN, op. cit., p. 46 e 52.

71 Ibid., p. 73-74. 
toda a transformação é a jurisprudência, refletindo a realidade social, além da doutrina e também dos costumes. Assim como o direito existe para transformar a ordem, construindo um mundo mais humano, assim, também a hermenêutica jurídica apresenta a crítica do que ocorre no mundo".72

As teorias críticas são um conjunto de críticas de paradigmas dominantes, do senso comum dominante dos juristas, e, contêm um significado como o trazido por COELHO, que diz: "não é o sentido da norma que impõe ao jurista, mas é o jurista que estabelece o sentido da norma de acordo com sua formação cultural e ideológica, de sorte que é o jurista a única e autêntica fonte do direito". ${ }^{73} \mathrm{Na}$ verdade, a hermenêutica jurídica crítica torna o intérprete um criador, atribuindo significados, revelando pressupostos ideológicos, tornase assim, na prática, a "única e autêntica fonte do direito".

Em nome da segurança jurídica, quer-se "manietar o juiz e minimizar a função judicial. Sucede que esse juiz-computador, esse aplicador mecânico de normas, cujo sentido não lhe é dado aferir, este juiz assim minimizado e desumanizado, não é, de forma nenhuma, capaz de realizar a segurança jurídica”. Preso à teoria, fica impedido de ver acontecer a vida, "o mais que poderá fazer é semear a perplexidade social e a descrença na função que deveria encarnar e que, por essa forma, nega. Ne- gando-a, abre caminho para o desassossego social e a insegurança jurídica". Assim, se "quiserem atentar ao clamor da vida, os juristas precisam desviar-se dos pressupostos positivistas, compreendendo que seu trabalho sobre o ordenamento jurídico há de ser crítico e abrangente dos diferentes aspectos de sua inserção social, que exprimem aspectos diversos da projeção humana no mundo". ${ }^{74}$

Exige-se hoje um trabalho criativo dos juízes, buscando soluções que sejam "capazes de ensejar a harmonia social e o aperfeiçoamento da ordem jurídica". E, assim, tenta-se mostrar as "potencialidades do processo hermenêutico, em que se insere o poder criativo dos juízes, adaptando as leis à concretude dos fatos, precisando-as, modificando-as, suprindolhes as lacunas, em face de novas necessidades humanas ou de caracteres novos que se acresçam a velhos fatos ou, ainda, de formas diversas de valorizar os mesmos fatos, advindas da evolução social". 75

\section{Considerações finais}

Por representar, a hermenêutica, a mais importante forma de interpretação do sentido das palavras e ciências, estando centrada numa categoria central, da Totalidade, tomou-se as contribuições hermenêuticas da obra Verdade e Método de HANS-GEORG GADAMER como ponto fundamental de nossas considerações, por

72 ANDRADE, op. cit., p. 152.

73 COELHO, op. cit., p. 182.

74 AZEVEDO, op. cit., p. 25.

75 AZEVEDO, op. cit., p. 69. 
entender ser ele um grande marco na história da filosofia e da interpretação hermenêutica.

Os objetivos desta pesquisa, desenvolvidos nos dois capítulos, primeiro - dentro da hermenêutica filosófica, com a compreensão, (ou da pré-compreensão que se tem das coisas), a interpretação e aplicação, além da discussão/contribuição sempre atual que ARISTÓTELES traz com suas ponderações sobre o papel da razão relacionado com a ética, também a viragem lingüística, com o rompimento da relação sujeito-objeto, que passou para a relação sujeito-sujeito, a questão da linguagem no mundo, que é anterior a nossa presença no mundo, e o problema do método, são fundamentais para a compreensão da importância que possui a filosofia ontem e hoje. Tudo gira em torno da filosofia, não há como discutir outros ramos/matérias do Direito sem se fazer uma menção a ela.

Neste sentido, também no segundo capítulo - dentro da hermenêutica jurídica, com ênfase na interpretação do Direito como um todo, além da análise da importância que possui a discussão do que seja o sistema jurídico, o método sistemático e tópico, com a abordagem de aspectos importantes da hermenêutica jurídica em nosso país e da hermenêutica jurídica crítica, comprometida, construtiva, atribuindo-se ao intérprete essa função de agente transformador da realidade social na qual nos encontramos.

Nas decisões judiciais, percebe-se tanto os "conceitos como os 'pré-conceitos"”, e, desta forma, a teoria crítica colocase como algo real transformador, pois visa construir um futuro melhor, "um mundo mais humano", neste sentido temos a contribuição hermenêutica jurídica que faz a crítica do que acontece no mundo, tornando o intérprete um criador do Direito, atribuindo significações, portanto seu trabalho deve ser crítico, criativo, na busca das melhores decisões, adaptando-se as leis aos fatos, frente às novas necessidades humanas e também às novas realidades.

Não há como se separar a compreensão da aplicação, nem a aplicação da interpretação, elas estão interligadas, e, mesmo certo de todas as dificuldades inerentes ao processo, e as dificuldades que o próprio intérprete (juiz) enfrenta diariamente com a questão da "decisão justa", deve-se continuar a perseguir a verdade e a justiça, como um ideal a ser atingido, buscando-se a concretização da garantia constitucional de acesso à ordem jurídica, o mais justa possível. Havendo uma necessidade crescente do aprofundamento crítico em relação ao Direito.

Existe, na verdade, uma necessidade muito grande em se formar intérpretes jurídicos, com uma visão ampla, consciente, séria, para o desempenho da tarefa/função, árdua por sinal, que, encontrando-se frente às antinomias (contradição entre duas leis ou princípios), possa ele fazer a melhor interpretação sistemática, fazendo do Direito um verdadeiro sistema normativo do Estado Democrático, tendo-se o desejo e a esperança de decisões "justas".

\section{Referências bibliográficas}

ANDRADE, Christiano José de. Hermenêutica jurídica no Brasil. São Paulo: RT, 1991.

ARISTÓTELES. Ética a nicômacos. Trad. Mário G. Kury. 2. ed., Brasília: Ed. UNB, 1992. 
AZEVEDO, Plauto Faraco de. Crítica à dogmática e hermenêutica jurídica. Porto Alegre: Fabris Editor, 1989.

BERTI, Enrico. As razões de ARISTÓTELES. São Paulo: Loyola, 1998.

BRANDÃO, Junito de Souza. Mitologia grega. Vol. 2. Petrópolis: Vozes, 1987.

COELHO, Luiz Fernando. Lógica jurídica e interpretação das leis. 2. ed., Rio de Janeiro: Forense, 1981.

DUSSEL, Enrique. Ética da libertação na idade da globalização e da exclusão. São Paulo: Vozes, 1999.

FREITAS, Juarez. A interpretação sistemática do direito. 2. ed., São Paulo: Melhoramentos, 1998.

GADAMER, Georg-Hans. Verdade e método. Traços Fundamentais de uma hermenêutica filosófica. Trad. Flávio Meurer. Rev. trad. Enio Giachini. 3. ed., Petrópolis: Vozes, 1999.

HABERMAS, Jürgen. Pensamento pós-metafísico estudos filosóficos. Rio de Janeiro: Tempo Brasileiro, 1990.

KELSEN, Hans. Teoria pura do direito. Tradução de João Baptista Machado. 6. ed., São Paulo: Martins Fontes, 1998.
LEITE, Eduardo de Oliveira. A monografia jurídica. 4. ed., rev., atual. e ampl. São Paulo: Revista dos Tribunais, 2000.

LUDWIG, Celso Luiz. A problemática questão do método. Texto inédito. . Razão hermenêutica. Texto inédito.

PASQUALINI, Alexandre. Hermenêutica e sistema jurídico. Porto Alegre: Livraria do Advogado, 1999.

SPAREMBERGER, Raquel Fabiana Lopes. Da hermenêutica à hermenêutica constitucional dos direitos fundamentais. Dissertação de Mestrado apresentada na UFPR em 19.06.2000.

STEIN, Ernildo. Aproximações sobre hermenêutica. Porto Alegre: EDIPUCRS, 1996.

STRECK, Lênio Luiz. Hermenêutica jurídica e $(m)$ crise - uma exploração hermenêutica da construção do direito. Porto Alegre: Livraria do Advogado, 1999.

VIEHWEG, Theodor. Tópica e jurisprudência. Tradução Tércio Sampaio Ferraz Jr. Imprensa Federal (Coleção Pensadores Jurídicos Contemporâneos). Brasília: DIN, 1979. 